\title{
Multimedia and Online Video Case Studies for Preservice Teacher Preparation
}

\author{
Terence R. Cannings and Sue Talley \\ Graduate School of Education and Psychology, Pepperdine University, 400 Corporate Pointe, \\ Culver City, CA, 90230, USA \\ cannings@pepperdine.edu
}

Keywords: case studies, teacher education, distance learning, multimedia, world wide web/website

\begin{abstract}
Case studies have been used successfully as a part of teacher education. There are many possibilities in extending the impact of case studies through the use of technology. Video and the Internet could enable demonstration of more examples, dissemination beyond the walls of the classroom, and discussion between geographically dispersed preservice teachers. Several projects are now investigating the possible ways that technology might enhance or extend text case studies. After exploring four existing products, four essential elements for video case studies are proposed. As video case studies move to the Internet, additional issues arise and these are also explored.
\end{abstract}

\section{SCENARIO}

Joe has the opportunity to use technology in his Math methods course. One of the demonstrations he sees in his face to face course is done by Paula Howe, a master teacher from a local school district who has actively worked to integrate appropriate technology with a very strong mathematics curriculum. Several other demonstrations are given by Dr. Lamp, the course instructor. Dr. Lamp also actively models the use of technology in the instruction of the course itself by appropriately using multimedia presentations. In addition, Joe uses many online resources to explore other possible technology resources that he can use in an elementary classroom. 
These resources include several video case studies that encourage students to explore and discuss the infusion of technology into learning. Joe also creates lessons that infuse the technology and uses them as part of his student teaching experience.

All of these technology resources represent current thinking about best practices and are correlated to the appropriate state and national curriculum standards and frameworks. To make this particularly easy to see, the materials are indexed according to elements of the curriculum as well as subject levels. Joe is able to indicate specific areas of interest, just as he might on an e-commerce site for purchasing books. This will tell him of any new resources that have been added that might be of interest.

It is difficult for a novice teacher to enter any classroom and feel comfortable with the demands placed on them. In addition to the demands expected of a novice in the more traditional curriculum areas, Joe is expected to integrate technology tools to improve student achievement, as exemplified in the above scenario extract. Teacher educators continue to search for effective strategies that will enhance the use of technology tools in the preservice program and ultimately in the novice teacher's classroom. Unfortunately, "despite increasing demand for technology use in the classroom, many teachers still feel they are ill-prepared to integrate these tools into the classroom" (Sprague et al. 1998, p.25).

When faced with the challenge of developing more teachers and making certain that these teachers are prepared to infuse technology into their classroom learning strategies, new ways of preparing preservice teachers are clearly needed. This paper will describe one such strategy, development and use of multimedia and online video case studies in teacher preparation programs.

\section{CASE STUDIES AND TEACHER EDUCATION}

Traditionally, text-based case studies such as those developed by Judith Shulman (1992) and Rita Silverman (1996) enable preservice teachers to reflect upon descriptive scenarios on teaching and learning within a given context. These case studies have emerged as a powerful tool for bringing the complexities of classroom activities into focus and supporting preservice teachers in connecting theory and practice. Lee Shulman (1992) recommended the case study methodology as an effective tool to create a bridge between principle and practice in an "engaging, more demanding, more intellectually exciting and stimulating..." way (Shulman 1992, p. 16).

Similarly, Wasserman (1994), Silverman, Welty and Lyon (1996) and Merseth (1994) advocate case study methodology as an appropriate 
pedagogical technique for teacher education. As Merseth (1994) stated, a case study is "...a descriptive research document, often presented in narrative form, that is based on a real-life situation or event. It attempts to convey a balanced, multi-dimensional representation of the content, participants and reality of the situation" (p. 16). The scenarios presented within the case studies are essentially a tool for discussion and interpretation for users with differing perspectives. The case studies can be viewed in different ways, "Case [study] purpose falls into three categories: (a) cases as exemplars; (b) cases as opportunities to practice analysis, the assimilation of differing perspectives, and the contemplation of action; and (c) cases as stimulants for personal reflection" (Merseth 1994, p. 18). Adoption of these three categories, as shown later in the paper, presents developers of future case studies with interesting challenges.

Implicit in studying such cases is the understanding that there are no clear-cut, simple answers to the complex issues teachers face on an hourly or daily basis. These cases describe nettlesome dilemmas, which are the stuff of daily classroom life. Effective text-based case studies demand active student engagement and promote the preservice teacher's ability to discern the essential learning and teaching elements in a given situation, and to analyse and interpret data to inform an action.

According to Wasserman (1994), five basic principles guide the construction and use of text-based case studies for use in teacher preparation:

1. Cases are well written, 'pack a wallop', do not end with a resolution and help explain the relationship between the big ideas in the case and the preservice course. Cases that end with a dilemma encourage open debate.

2. Appended to each case is a list of study questions, which call for thorough examination of important issues raised by the case.

3. The small group's work ideas are discussed and tried out in the safest context.

4. Debriefing a case places great skill on the way the instructor interacts with the students.

5. In follow-up sessions, effective case method teaching allows students to grow away from a desperate quest for right answers and solutions. (p. 16)

With increased Internet bandwidth, preservice students can now view video segments simply by accessing a website. That is, they can watch the action rather than just read about it. They can see and hear the teacher and students as they interact in the classroom. But do the same principles for designing and using text-based case studies apply to the online video version? 


\section{MULTIMEDIA AND ONLINE VIDEO CASE STUDIES}

Emerging technologies, such as digital video and editing, more powerful CPUs, and DSL and cable delivery services, have now made available new instructional possibilities and multiple ways of presenting video case studies. Video, with graphic and text-based support, can capture the complexity of classroom interactions enabling preservice teachers to view the 'real' teaching and learning strategies utilised by the teacher. This video allows a group of students to share a common experience and review, perhaps over several sessions, important or critical teaching strategies missed in earlier viewings. As Barron and Goldman (1994) suggest, "from our own experience in using integrated media with preservice teachers, and from similar research and development efforts at other institutions, we are encouraged about the use and potential of such materials in preparing teachers for the challenges of the classroom" (pp. 104-105). But technology tools and delivery systems have changed greatly since 1994 with the Internet now the predominant delivery system.

According to Perry (2000), "the Internet and multimedia, which includes the non-linear integration of video, audio, graphics, and text, can provide a rich environment for case studies that promote the construction of knowledge about integrating technology into the curriculum in a learning community of peers and faculty facilitators" (p. 4). With advancements in web delivery, this environment can be accessed anytime and anywhere in a convenient and cost-effective way. Lindeman et al. (1995) support this claim by arguing that the web provides a new vehicle for delivering video cases to learners with the ability to transmit text, graphics, sound, short video clips, and hypertext. In addition, Kovalchick, Hrabe, Julian and Kinzie (1999) suggest that the web provides "three significant capabilities for the delivery of case studies: (a) the ability to simulate real-world complexities, (b) the ability to use multiple media in case presentations, and (c) the ability to use hyperlink/hypertext navigation features" (p. 145).

At two recent symposiums (AERA, New Orleans and US Department of Education, Atlanta, 2000) that focused on the development of online video case studies, several questions were raised as to the optimal use of this strategy: Do we show best practices or teaching dilemmas? Are the videos real or staged? Do the videos include single incidents or composite incidents? How should an instructor best use online discussion with video case studies? What are the intellectual property issues? Can we include children in online video case studies? How can we avoid surface mimicking and promote learning of best practices? See Online Video Case Study Conference Web site references: 
New Orleans:

http://www.intime.uni.edu/ovcs/pedagogy/discussion1.htm and Atlanta:

http://www.intime.edu/ovce/the_conference/atlantaconference.htm

These discussions indicate that while video case studies have the potential to be an effective instructional tool for preservice teacher education there is still no definitive understanding of how best to use these technologies for optimal teaching and learning practices. In an attempt to create a list of essential multimedia and online video characteristics a brief review of four selected products is presented.

\section{CURRENT MULTIMEDIA AND ONLINE PRODUCTS}

In this section, three multimedia (CD-ROM) and two online video case studies are reviewed. For each example, a brief description of the case study, its use, and distinguishing features is given. Screen shots are included as appropriate.

a. Understanding Teaching: Association for Supervision and Curriculum Development (ASCD) and Arizona State University (1997).

"Understanding Teaching: Implementing the NCTM Professional Standards for Teaching Mathematics" provides firsthand observational experience that models the National Council of Teachers of Mathematics (NCTM) Professional Teaching Standards. The program incorporates a natural interface that situates learners in a real-world classroom environment. Four CD-ROMs utilise hours of classroom video, expert audio commentary, and 3-D graphics and animations that model math instruction. The program can be used as a stand-alone tool but it is suggested that two people or a community of practice $(\mathrm{CoP})$ use the program to increase interaction and facilitate learning (see Figure 1). Several features are particularly worthy of note. There is a notebook option that can be used to archive the CoP's reflections. The product consists of 46 video vignettes and animations that model NCTM Teaching Standards. There are also 8 videos available for evaluating the CoP's ability to identify which NCTM standards they see in the videos.

In essence, this product is designed to help pre- $\mathrm{K}-6$ teachers recognise, understand, and explain the NCTM Professional Standards for Teaching Mathematics. 


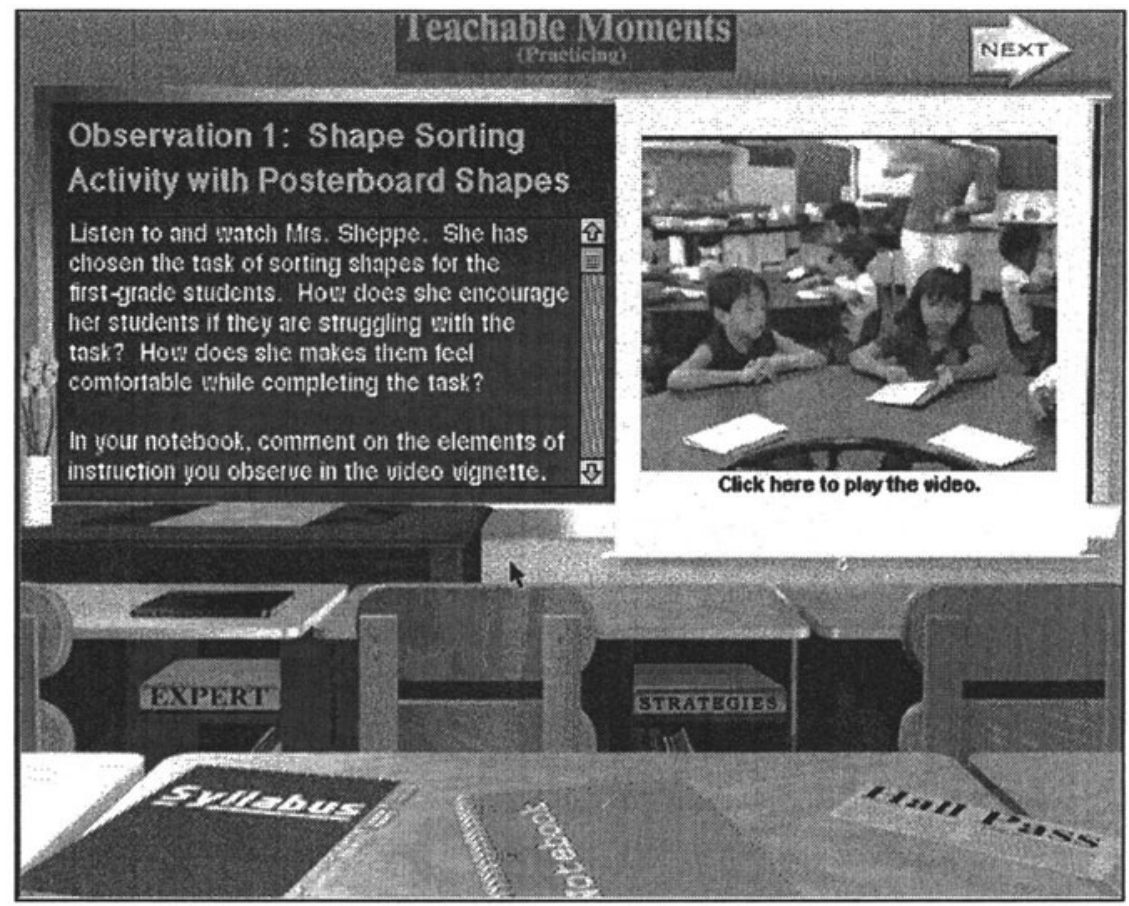

Figure 1. A 'Teachable Moment'

b. Making Weighty Decisions: Syracuse University, New York (1999).

This video case study was designed to help preservice teachers understand the complexity of the classroom, become better observers of classroom interactions, and learn to reflect on their own developing practice. This case study can provide a common context within which interesting aspects of an eighth-grade mathematics lesson implemented in a real classroom can be discussed, analysed, and understood in terms of the preservice teacher's developing practices. The facilitator of this case study can use this multimedia case to develop themes or highlight incidents that are of interest in the professional growth and development of preservice teachers (see Figure 2).

The classroom video consists of about 40 minutes of edited video for each day of the four one-day lesson sequences. Additional materials are included such as the seating chart, teacher reflections, and lesson plans. In essence, the video case study has organised the issues of teaching and learning mathematics that can be explored in four categories: lesson planning, facilitating classroom interaction, understanding student thinking, and mathematical content and context. 


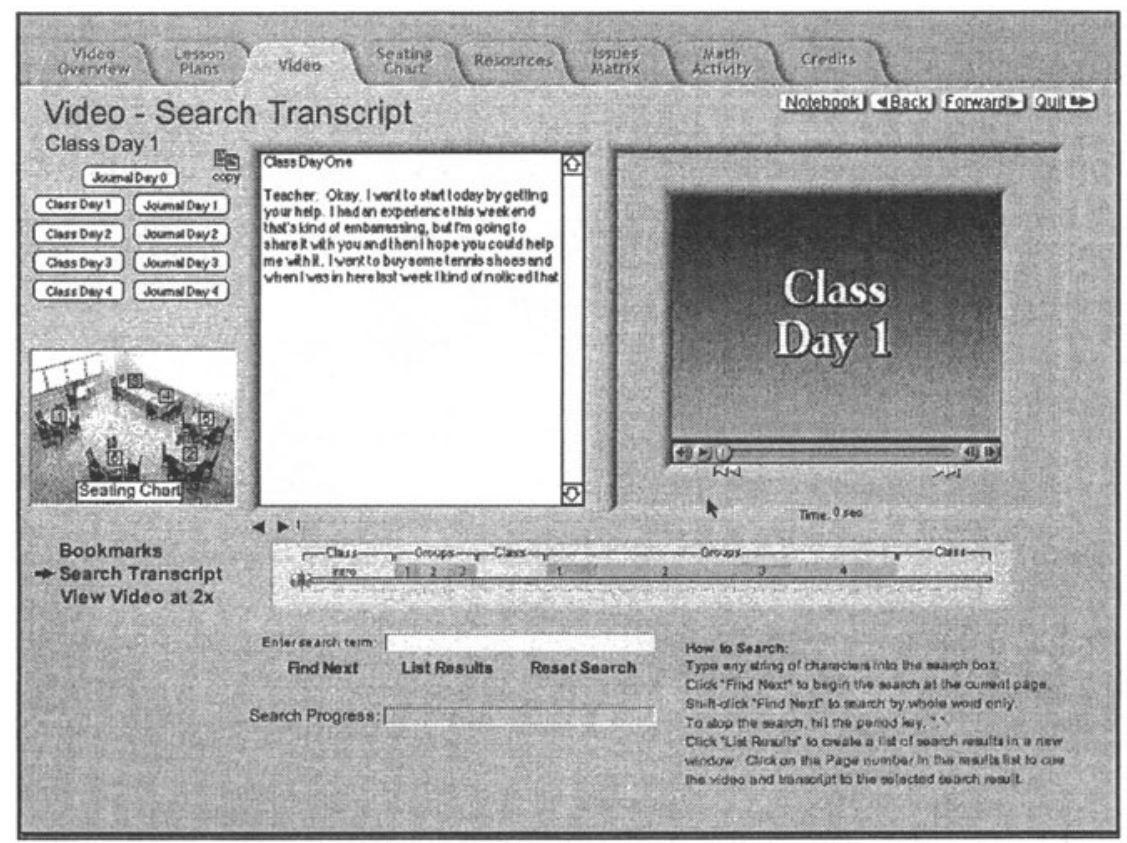

Figure 2. Video transcript search

c. A Classroom View: Austin Independent School District and the University of Texas, Austin (1999).

This product is an interactive multimedia program for educators. The CD-ROM contains more than 150 video vignettes of authentic pre-K-12 classroom environments with ready-to-use Units of Practice, teacher-created templates, and an extensive explanation about the district's Stages of Technology (SoT) integration. Using the word processing application as the focus, users are lead through the identified SoT (Integrating Change, Taking Control, Extending Your Reach, and Creating New Worlds) at a chosen grade or academic level.

Video vignettes from 16 host classrooms representing all academic levels are included, representing four stages of integration. 32 Units of Practice (applied ACOT research) are demonstrated for teachers to adapt for their own use.

An observation is coupled with a video segment to facilitate the user in identifying the NCTM Teaching Standard illustrated in the video segment.

The video screen has room for a text display of comments as well as video of the classroom interactions. The Search function allows the user to search for specific items within the transcript and the corresponding video clips of classroom interaction. In addition, a small version of the visual 
seating chart allows the user to more easily follow student interaction in the video.

d. In Time (Integrating New Technologies Into the Methods of Education): University of Northern Iowa (2000).

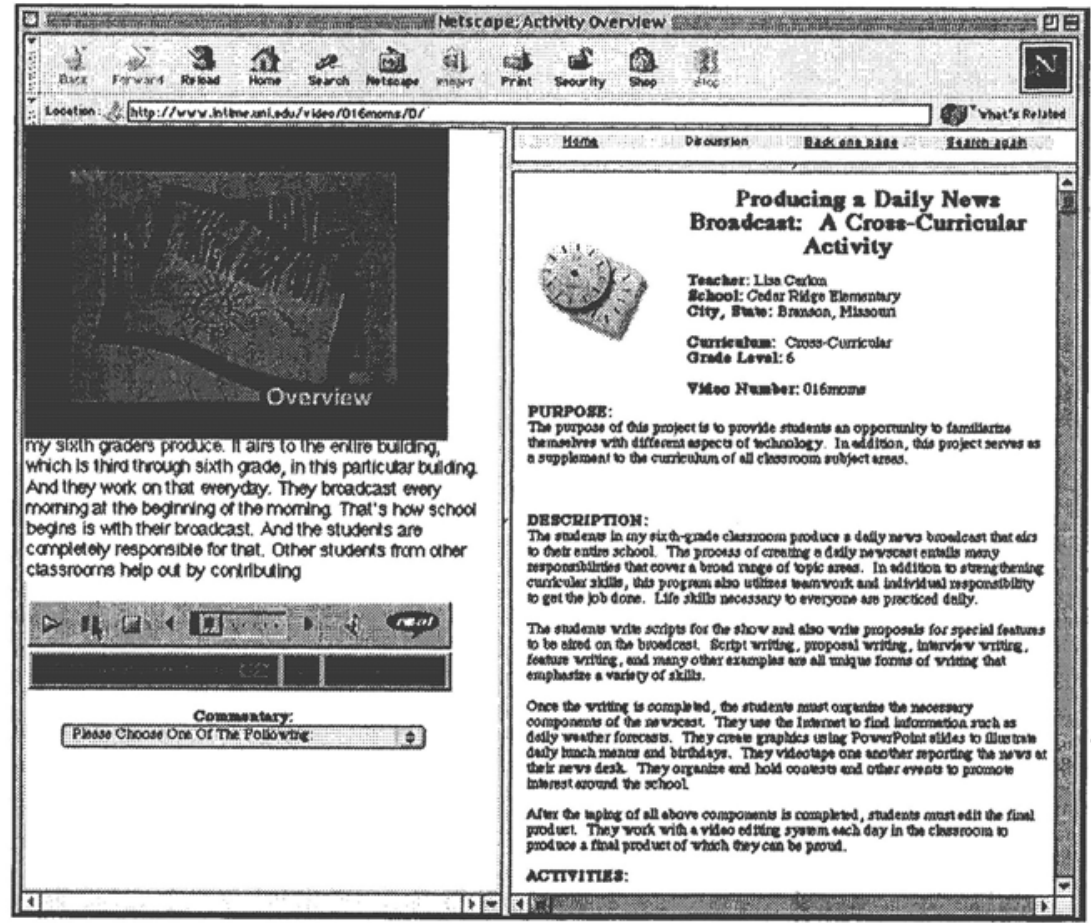

Figure 3. Activity overview.

The purpose of InTime is to provide the resources for methods faculty to use in revising their courses, modelling technology integration, and assisting preservice teachers to integrate technology into their lesson units (http://www.intime.uni.edu/about/about.html). The InTime project includes the development of video scenarios of pre-K-12 teachers effectively integrating technology, along with components of quality education, in a variety of grade levels and content areas. Faculty uses the video scenarios and online discussion forum to model technology integration (see Figure 3).

A wide variety of classroom videos in related content areas are shown along with rolling text aligned with the audio. The entire approach is based on a model of 'Technology as Facilitator of Quality Education.' 


\section{ESSENTIAL ELEMENTS FOR CREATING MULTIMEDIA/ONLINE VIDEO CASE STUDIES}

A review of the previously mentioned products, projects and research suggests that some elements are effective in video case study development.

1. An engaging tool interface. The tools available to encourage ongoing observation, dialogue and reflection should include, but not be limited to, teacher reflection on lesson planning and delivery, audio or video contextual clues, asynchronous and synchronous discussion, a user journal reflection tool, and access to additional resources such as web sites and content experts discussing the case study.

2. An ongoing communication system. Preservice teachers, through their community of practice, require asynchronous tools such as a threaded discussion to engage in reflective dialog. Preferably, a synchronous chat room should be present which will enable facilitators to further engage the preservice teachers in real-time dialog on the case study. These tools may require partnerships with other organisations which have developed exemplary models in this area.

3. Contextual clues for viewing. The inclusion of the teacher's voice reflecting on planning the actual lesson and the lesson itself with background data on the school, students, and classroom activities provides the user with contextual clues within which the video case study is viewed. These contextual clues can be presented in text-based, graphic, audio or video formats.

4. Access to additional resources. Web-based programs enable the frequent update of relevant resource material aligned to video case studies. Preservice students can access articles, references, and commentaries related to the teaching and learning process as well as the content areas.

InTime models various ways for preservice teachers to integrate technology. In this activity overview, the user is able to see a full text description of the activity details along with video and a rolling transcript of the audio.

\section{ISSUES IN THE DEVELOPMENT OF ONLINE VIDEO CASE STUDIES}

Many of the products reviewed above were produced in a CD ROM format. As these products move to the web, additional issues arise.

1. Philosophical approach to development. Three different approaches can be taken: (a) 'best' or 'exemplary' practice illustrating the practices to 
which a preservice teacher should aspire; (b) a dilemma asking the users to create strategies to answer the dilemma; (c) an approach like that used in the medical field, similar to that experienced in an Emergency Room, where users can manipulate different factors within the environment. The larger issue with online video case studies is the impact of the video on contextualising the practice. Is it possible that the video provides too much context, making the example too specific?

2. Length of video segments. Although no empirical study has been conducted, many of the current projects use 3 minute up to 8 minute video clips illustrating parts of a connected lesson or clips of selected concepts. These numbers reflect current bandwidth constraints. It is still unclear whether there should be even shorter videos (1 minute or less) supplemented with other materials or whether the videos must be even longer than 8 minutes.

3. Online bandwidth requirements. Bandwidth obviously impacts download capabilities of video, which can be accessed through progressive download or streaming. What technology takes best advantage of the bandwidth available? What techniques should be used to allow for the range of bandwidths from $56 \mathrm{~K}$ through DSL and cable?

4. Real or staged videos? Capturing the action in a real classroom can present an audio challenge. While the video is important, recording good audio is critical. This factor alone may necessitate video case studies of staged classrooms. How much of the video can be staged and still capture the realities of the classroom?

5. Appropriate video production. Standard video production technologies must be adapted for web use. Large group shots, zooming and camera sweeps of classrooms don't present well on the web. Of greater importance is the availability of good quality audio recording of interactions between students and teacher and student-student interaction. What techniques work best for the web?

6. Role of facilitator. Although the video case studies can be used as standalone materials, online facilitation, in our opinion, is critical to optimal impact of this approach. What are the expectations for the role of this facilitator?

\section{SUMMARY}

In summary, multimedia and online video case studies enable preservice teachers to reflect on classroom practice that they might otherwise not experience. Preservice students can view complex, interactive situations that are in a constant state of flux and can begin to acquire pedagogical tools for 
situations in which there are no easy, clear-cut answers. Ongoing development and analysis of multimedia and online video case study projects will enhance efforts to provide preservice teacher educators with additional tools and strategies for integrating technology into pre-K-12 classrooms.

\section{REFERENCES}

Barron, L. C. and Goldman, E. S. (1994) Integrating technology with teacher preparation. In Technology and education reform: The reality behind the promise, B. Means (ed.), JosseyBass, San Francisco, pp. 81-110.

Kovalchick, A. M., Hrabe, E., Julian, M. F. and Kinzie, M. B. (1999) ID case studies via the World Wide Web. In The ID casebook: Case studies in instructional design, P. A. Ertmer and J. Quinn (eds.), Merrill, Prentice Hall, New Jersey, pp. 141-148.

Lindeman, B., Kent, T., Kinzie, M., Larsen, V., Ashmore, L. and Becker, F. (1995) Exploring cases on-line with virtual environments. Curry School of Education, University of Virginia. [http://www.csc 195.indiana.edu/csc195/-lindeman.html] 5.21.2000.

Madfes, T. J. and Shulman, J. H. (2000) Dilemmas in professional development: A case-based approach to improving practice. McGraw-Hill, New York.

Merseth, K. (1994) Cases, case methods, and the professional development of educators. (digest ED401272), ERIC Digest Number: 95-5.

Perry, G. (2000) Video case studies and teacher education: A new tool for preservice education. Unpublished manuscript, Pepperdine University, Culver City, CA.

Shulman, J. H. (1992) Case methods for teacher education. Teachers College Press, New York.

Shulman, L. (1992) Toward a pedagogy of cases. In Case methods in teacher education, J. H. Shulman (ed.), Teachers College Press, New York, pp. 1-30.

Silverman, R., Welty, W. M. and Lyon, S. (1996) Case studies for teacher problem solving. $2^{\text {nd }}$ ed., McGraw-Hill, New York.

Spiro, R. J. et al. (1988) Cognitive flexibility theory: Advanced knowledge acquisition in illstructured domains. Tenth Annual Conference of the Cognitive Science Society. Hillsdale, Erlbaum, NJ.

Sprague, D., Kopfman, K. and de Levante Dorsey, S. (1998) Faculty development in the integration of technology in teacher education courses. Journal of Computing in Teacher Education, 14 (2), pp. 24-28.

Wasserman, S. (1994) Introduction to case methods teaching. Teachers College Press, New York.

\section{BIOGRAPHY}

Terence Cannings currently serves as Associate Dean of Education at the Graduate School of Education and Psychology (GSEP) at Pepperdine University. Under his leadership the Education Division received a Catalyst Grant from the U.S. Department of Education for Pre-service Teacher 
Education \& Technology Preparation. His current research interests are in distance learning and technology use in teacher education. Recent activities have included presentation to The Glenn Commission in Washington D. C. and a month in China as part of the People to People Ambassador Program in teacher education. 